\title{
The Human Domain of Cyber: Islamic State's Asymmetric Information Campaign
}

\section{Elizabeth Oren}

The purpose of this report is to broaden the impact of military and legal measures against Islamic State and global affiliates through a counter information campaign in the Human Domain ${ }^{1}$ of Cyber. The Human Domain of Cyber is defined as the human domain in the operational environment and the intersection with technology. This report utilizes Cyber Humanics ${ }^{\circledR}$ advanced tradecraft to create recommendations for NATO Member and Partner nations on countering Islamic State's online asymmetric recruitment of foreigners on social media. Cyber Humanics ${ }^{\circledR}$ is the advanced tradecraft and methodology to holistically study and analyze contemporary media, data technology, and the human element in the digital sphere. All recommendations are based on social media analysis of Islamic State's multi-dimensional online recruitment materials in Russian, Turkish, French, and English examined on two levels: (1) the organizational level, referencing materials officially published by the Islamic State; and (2) the individual level, analyzing unofficial content from public Islamic State supporter social media accounts.

* This document is subject to copyright 2020 and was originally disseminated in limited distribution entitled: Report on Islamic State's Asymmetric Information Campaign NATO SCHOOL Oberammergau, Germany. January $5^{\text {th }}$ 2015. The information and views expressed in this report are solely those of the author and may not represent the views of the University of Texas at Arlington and associated organizations, NATO, ACO, ACT, NATO School Oberammergau, or NATO member countries.

1. Votel (General), Joseph. "Operating in the Human Domain." USSOCOM Publication, 3 Aug. 2015. 


\section{| Introduction}

The crux of the fight against Islamic State (IS $)^{2}$ is recruitment attrition by means of decreasing ideological support for IS's cause. Even though US, UAE, SA, and Syrian Government airstrikes aimed at IS strongholds and financial resources, ${ }^{3}$ suspension of pro-IS social media accounts, ${ }^{4}$ and travel bans to Syria can collectively reduce IS capacities and fighters, these tactics do not actually counteract influential cultural and ideological motivations. This is why IS support and propaganda dissemination still continues outside of official IS channels as demonstrated by the identity exposure of ShamiWitness, who turned out to be an executive in India favoring IS on Twitter. ${ }^{5}$ With this in mind, this report: (1) defines IS recruitment attrition and explains why it is crucial for NATO Member and Partner state security, (2) links pertinence to future and potential NATO capacity and security building missions, (3) demonstrates why IS recruitment is asymmetric, and (4) offers tailored recommendations for IS recruitment attrition.

The IS recruitment process is asymmetric in that it occurs within local communities and online virtual spaces capitalizing on ideological, financial, and situational motivations. Online IS recruitment includes official Al-Hayat $t^{6}$ publicity and unofficial supporter generated content that promotes IS objectives, advertises joining or establishing IS communities, and influences individuals to kinetically augment IS combatant forces. The encompassing nature of online IS recruitment is why recruitment attrition operations should encompass actual and potential recruitment pools including foreign jihad fighters, supporters, and empathizers living abroad or domestically.

The focus of this report is online recruitment that expands the IS foreign fighter and non-combatant community. Online IS recruitment targets Muslim communities outside of Syria and Iraq to increase hijrah $^{7}$ to IS territories and/or to promote IS modeled insurgencies in other Muslim states. This is why IS's recruitment strategy advertises to a broad Muslim audience for universal community building [Figure 1] then tactically shifts to localized messaging.

The Alliance has a specific stake in IS recruitment

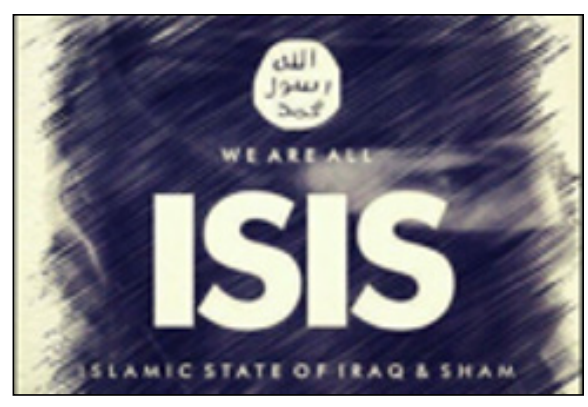

Figure 1: Communal IS propaganda meme attrition because this trend impacts global security, and NATO member state domestic security. Thousands of NATO Member and Partner nationals have joined

2. Islamic State (IS) represents ISIS, ISIL, and Da'ish; the usage of the term "state" does not signify official statehood.

3. Pirinççi, Ferhat, Oytun Orhan and Bilgay Duman. "US Strategy Against ISIS and Its Potential Implications for Iraq \& Syria." ORSAM, Sep. 2014, http://www.orsam.org.tr/en/enUploads/Article/Files/2014924_rapor191ing. pdf. Accessed Sep. 2014.

4. Borison, Rebecca. "Twitter Suspended An ISIS-Affiliated Account That Called For The Assassination of Twitter Employees." Business Insider, 9 Sep. 2014, http://www.businessinsider.com/twitter-suspended-isis-affiliatedaccount-that-called-for-its-assassination-2014-9. Accessed 9 Sep. 2014.

5. "@shamiwitness: India arrests man over pro-Islamic State tweets." BBC Asia, 13 Dec. 2014, http://www.bbc. com/news/world-asia-30461455. Accessed 13 Dec. 2014.

6. Al-Hayat content is marked by a seal released by IS publicity.

7. Historically, Prophet Muhammad's migration from Mecca to Medina; implied immigration to the Islamic State. 
IS's war campaigns contributing to international conflict, and instability in Syria and Iraq. ${ }^{8}$ Generally, IS foreign fighters and non-combatant recruits move for the duration, destroying passports and identification papers. ${ }^{9}$ However, domestic threats still exist for NATO member states from IS devotees who could be directed, or independently motivated as witnessed by the 2014 Jewish Museum attack in Brussels by former IS foreign fighter Mehdi Nemmouche. ${ }^{10}$

Equally, the IS community is a danger to NATO missions in Afghanistan as evidenced by the November 2014 Taliban and IS Afghan affiliate attacks on Shorabak. ${ }^{11}$ In Libya, the IS affiliate Majlis Shura Shabab al-Islam in conjunction with Ansar al-Sharia thrusted the city of Darnah into an IS modeled caliphate in April 2014. ${ }^{12}$ Even though there is not a NATO security and capacity building mission currently grounded in Libya, any policy change will mean facing IS foreign fighters in Libya. Armed, global IS movements put any Muslim state, or region with grave internal security weaknesses at high risk for an IS based insurgency.

Despite the tactical effectiveness of the 2014 international coalition airstrikes on IS financial and military assets, ${ }^{13}$ tomorrow's new combatants can still replace those killed yesterday. Additionally, IS jihad fighters who are unsuccessful at traveling to Syria are creating global spillover and battlefield substitution much like would-be Emirate Caucasus fighters deflecting to combatant bands in Syria, ${ }^{14}$ and Afghan Taliban retreating into Pakistan. ${ }^{15}$ Also, IS encourages jihad fighters to push forward in

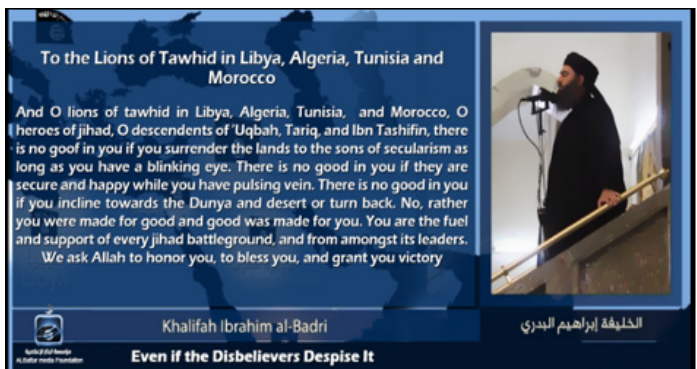

Figure 2: IS Caliph al-Baghdadi's address to IS affiliates in Libya, Algeria, Tunisia, and Morocco (2014) Libya, Algeria, Tunisia, and Morocco to augment IS affiliates [Figure 2].

As we look to the future of hybrid warfare, the element missing from the 2014 international coalition airstrikes against IS is an equally effective asymmetric information campaign addressing ideological motivations for supporting IS. Pulled from an anti-IS American social media account [Figure 3] illustrates the deficit in Western perception of all the asymmetric warfare tactics utilized by IS. The arsenal of IS bands are no match for the awesome firepower

8. "Islamic State crisis: '3,000 European jihadists join fight." $B B C$, 26 Sep. 2014, http://www.bbc.com/news// world-middle-east-29372494. Accessed 26 Sep. 2014.

9. Based on IS foreign fighter and foreign non-combatants testimonies.

10. Rouiller, Jean-Paul. "From MM (for Mohamed Merah) to MN (Mehdi Nemmouche) or the Foreign Fighters Shifting Paradigm." NATO COE-DAT Terrorism Experts Conference, 2014, Turkey. Conference Presentation.

11. "Afghan Troops 'Drive Out' Taliban From Key Southern Base." RFERL Afghanistan, 15 Dec. 2014, http:// www.rferl.org/content/helmand-attack-afghanistan-shorabak-camp-bastion/26714774.html. Accessed 15 Dec. 2014.

12. Zelin, Aaron Y. "The Islamic State's First Colony in Libya". The Washington Institute, http://www. washingtoninstitute.org/policy-analysis/view/the-islamic-states-first-colony-in-libya. Accessed 10 Oct. 2014.

13. Pirinççi, Ferhat, Oytun Orhan and Bilgay Duman. "US Strategy Against ISIS and Its Potential Implications for Iraq \& Syria." ORSAM, Sep. 2014, http://www.orsam.org.tr/en/enUploads/Article/Files/2014924_rapor191ing. pdf. Accessed Sep. 2014.

14. Statement based on media analysis of Russian-speaking jihad fighters in Syria, research on Chechen Government anti-terror policies, and the movement of North Caucasian jihad fighter trends from 2010-2014.

15. "Learn from Yesterday, Gain for Tomorrow NATO's Counter-Terrorism Experience in Afghanistan." Lessons Learned Workshop, NATO COE-DAT, 18 Nov. 2014, Ankara, Turkey. 
aboard an aircraft carrier, but despite the extraordinary capabilities of NATO member and partner states the same conflicts are not being engaged.

IS and supporters actually utilize the international coalition airstrikes to embolden IS recruitment by posting images of dead non-combatants and infrastructure damage, which is marketed as a direct war against Islam [Figure 4]. This type of broad global recruitment of Muslims is primarily taking place in a world of framed reality on free social media. Within this online world lies a great potential for NATO nations to reduce the number of individuals kinetically augmenting IS and affiliates, and to decrease broad support for IS's activities. In order to engage this aspect of IS's war campaign, social media analysis needs to be paramount in information gathering. Then, this gained information can be used towards the counter narrative against IS, and counter information operations.

It is vital to recognize that the IS recruitment process is multi-dimensional and adaptive [Figure 5] meaning that counter information operations must be flexible. When is supporter social media accounts and websites are removed or suspended these accounts reappear under new user names gaining followers quickly, and content is redirected to new platforms. ${ }^{16}$ Currently, many official recruiters are under locked accounts, and many public pro-IS accounts are not officially linked to IS. However, the public content actually resonates with the target audience who consequently widen the popularity of these accounts.

IS recruitment mirrors the asymmetric warfare tactics of IS in that the process is complex, adaptive, and comprises a myriad of actors and methods. An evolving specialized information campaign based on cultural intelligence and analysis can extend the impact of military and legal measures for global IS recruitment attrition. The following recommendations are tailored to ideological and cultural motivations for joining IS, and are intended for online

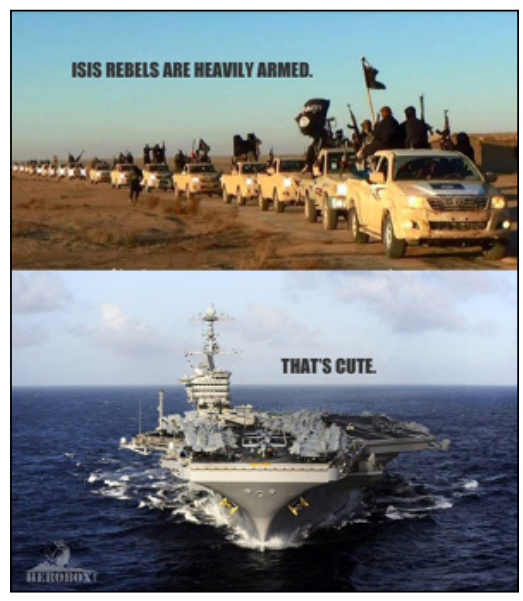

Figure 3: Anti-IS meme contrasting firepower capacity (2014)

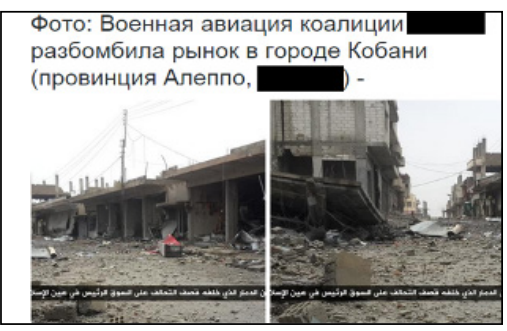

Figure 4: Pro-IS account attributing the damage in an Aleppo province market to coalition airstrikes (2014)

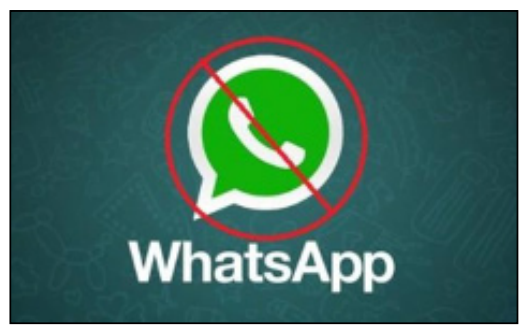

Figure 5: IS WhatsApp ban. Individuals who have valuable information for IS operations are being instructed via this anti-WhatsApp meme to not use the app (2014) implementation.

16. Assessment based on monitoring of IS supporter social media accounts in real-time. 


\section{Recommendations}

1.1 Without defining Islam, define Islamic State as an illegitimate vigilante caliphate in order to fixate a key counter narrative.

1.2 Without polarizing Sunnis, label Islamic State neo-khawarij ${ }^{17^{*}}$ who make takfir ${ }^{18^{*}}$ on Muslims for recruitment attrition, and to increase the division between Islamic State and other jihadi combatant groups.

1.3 Directly counter the opinion held by Islamic State empathizers and supporters who believe: (1) there is a war against Islam and (2) Muslims are only free in IS's caliphate, in order to reduce global support for Islamic State.

1.4 Derive counter content from cultural intelligence analysis of Islamic State recruitment materials and the pop culture of jihad fighters.

1.5 Define distinct motivations for joining and supporting Islamic State and target accordingly in order to achieve attrition among the different Islamic State recruitment pools.

1.6 Localize all counter Islamic State content in order to effectively reach the global multilingual Islamic State target audience.

1.7 Compose counter content from the viewpoint of Islamic State empathizers and vulnerable audiences in order to connect with the target audience.

1.8 Format counter content that resonates with the human aspect of the Islamic State community.

1.9 Format counter materials specific to female motivations for joining and supporting Islamic State in order to reduce the number of children raised to augment Islamic State forces.

1.10 Design counter materials aimed at the global Islamic State virtual community in order to deter Islamic State militant movements outside of Syria and Iraq.

1.11 Design counter materials for the generational culture of Islamic State jihad fighters and supporters so that the target audience is entertained by the messages.

1.12 Counter Islamic State online recruitment methods in real time in order to reduce the impact of trending comments, false news, and conspiracy theories.

1.13 Monopolize on Islamic State's quick information dissemination and pro-Islamic State social media users who divulge valuable information.

1.14 Utilize social media accounts to subtly erode credibility of major Islamic State recruiters and proponents on social media.

17. Historically, khawarij or kharijites deviated from the teachings of the Prophet and rebelled against the Caliphate.

18. Being a takfiri or making takfir occurs when a Muslim accuses another Muslim of apostasy. 


\section{Recommendations}

1.1 Without defining Islam, define Islamic State as an illegitimate vigilante caliphate in order to fixate a key counter narrative.

By defining IS as an illegitimate vigilante caliphate, the narrative places IS in a corner because it encompasses IS's own words in a negative label. Additionally, it will push IS to change its approach in order to survive politically and socially. The vigilante term is fitting because IS declares to avenge Shia oppression against Sunnis, and IS declares to establish order and justice in a brash and forceful manner. ${ }^{19}$ IS does actually implement some Islamic law [Figure $6 \&$ 7] but labeling IS as an illegitimate caliphate with evidence from Islamic law can verify illegitimacy to the target audience.

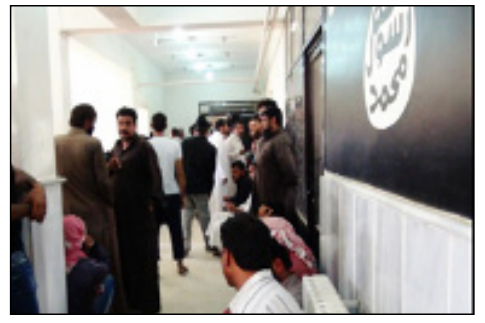

Figure 6: IS courthouse in Syria

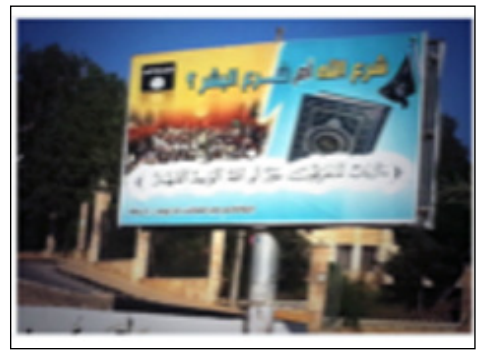

Figure 7: IS billboard "God's law not man's law" in Syria (2014)

1.2 Without polarizing Sunnis, label Islamic State neo-khawarij who make takfir on Muslims for recruitment attrition, and to increase the division between Islamic State and other jihadi combatant groups.

The term neo-khawarij brands is as a modern version of notorious Muslim radical rebels advertising under the flag of Tahwid. IS members are Sunnis, but many Sunni opponents consider IS as khawarij and takfiris [Figure 8]. Khawarij is religiously pertinent, translatable to all Muslim cultures, and negative. This term also decreases broad Sunni Muslim support without polarizing Sunnis.

Additionally, IS accuses non-IS Muslims as being apostates, which is making takfir. The takfir approach forces Muslims to support or fight IS. This creates a confrontation between IS and jihadi combatant bands in Syria [Figure 9], the North Caucasus, al-Qai'da, and Jabhat al-Nursa.

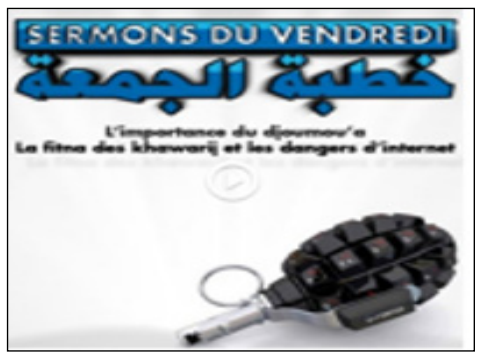

Figure 8: Islamic online sermon about the danger of khawarij (2014)

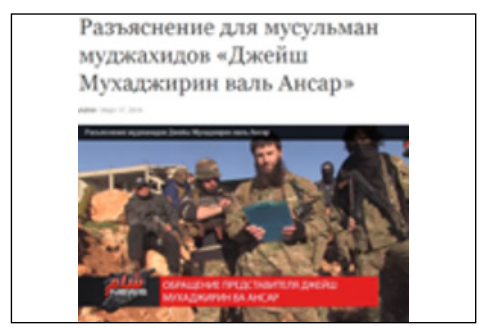

Figure 9: Jaish al-Muhajireen wal-Ansar making a case against an IS leader

19. Al-Abdeh, Malik. "The Transition of Groups from Terrorism in Insurgency and the Case of Population Support of Syria." NATO COE-DAT Terrorism Experts Conference, 2014, Turkey. Conference Presentation. 
1.3 Directly counter the opinion held by Islamic State empathizers and supporters who believe: (1) there is a war against Islam and (2) Muslims are only free in IS's caliphate, in order to reduce global support for Islamic State.

These two beliefs held by IS and other global jihadi combatant organizations/bands is the pith of foreign fighter recruitment and IS supporters [Figure 10]. Additionally, many foreign jihad fighters augment various bands with the intent to help Syrians, defend Muslims, and live under Shari'ah. This is important because some Muslims believe that they are only free and true Muslims if living under Shari'ah; actual discrimination and persecution of Sunni Muslims is used as evidence to support this belief. Since IS has made concrete progress for a caliphate, IS is able to endorse that Sunnis can only live freely and comfortably as Muslims in IS's caliphate [Figure 11].

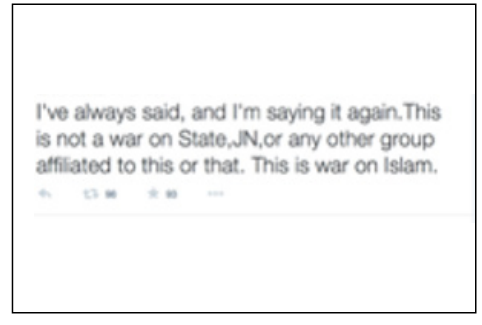

Figure 10: IS fighter commentary on social media

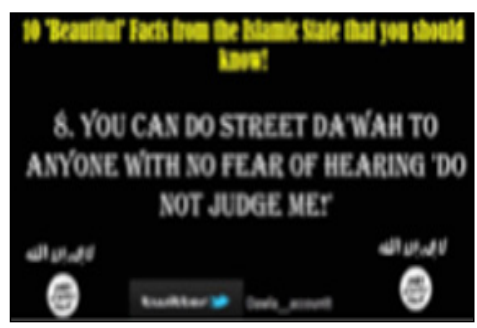

Figure 11: IS meme promoting liberty from judgment for Muslims (2014)

1.4 Derive counter content from cultural intelligence analysis of Islamic State recruitment materials and the pop culture of jihad fighters.

IS and other jihad fighter groups have a particular pop culture that requires understanding and appreciating in order to produce effective counter information. Individuals who are labeled as terrorists by governments are often viewed and honored as mujahideen by individuals [Figure 12]. This sentiment is also found in many Muslim communities regardless of support for militant activity, and creates a significant social wedge for counter terrorism and counter insurgency. ${ }^{20}$ This is one example of how cultural intelligence can

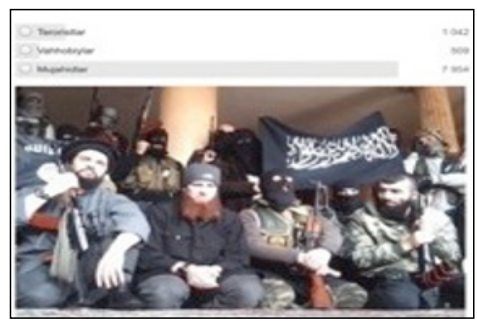

Figure 12: Online poll asking viewers to rank Omer Shishani's band of IS as a) Terrorists 1,042 b) Wahhabis 509 or c) Mujahideen 7,954 enhance how we address international security challenges.

20. Feyyaz, Muhammad. "Voids, Limitations and Their Implications in National Counter-Narrative for CT - A Case of Pakistan." NATO COE-DAT Terrorism Experts Conference, 2014, Turkey. Conference Presentation. 
1.5 Define distinct motivations for joining and supporting Islamic State and target accordingly in order to achieve attrition among the different Islamic State recruitment pools.

Even though most foreign jihad fighters are motivated to defend and help Muslims, and to live under Shari'ah, not all jihad fighters actually support IS. This is why IS recruitment materials are purposefully tailored to each target audience culture, using testimonials from IS fighters who offer a high degree of legitimacy to sway other jihad fighters with similar backgrounds. The IS fighter in [Figure 13] explains why he consecutively left Emirate Caucasus, and Jabhat al-Nursa. However, this represents only a certain pool, while others augment IS forces for different reasons and each reason needs a particular message.

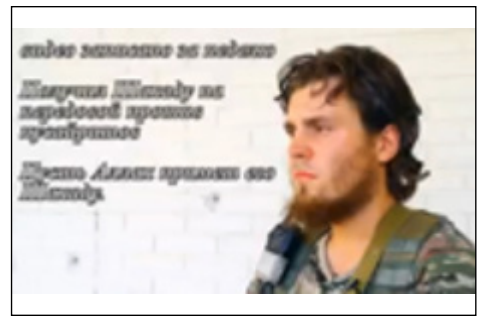

Figure 13: IS jihad fighter explaining why he left Emirate Caucasus and Jabhat al-Nursa. Russian language(2013)

1.6 Localize all counter Islamic State content in order to effectively reach the global multilingual Islamic State target audience.

As more IS content is localized in new languages, and online users promote the content, new target markets will be vulnerable, and IS foreign fighter and immigrant populations can increase and diversify. IS counter information needs to be localized content in order to reach the global target audience. Localization customizes advertising for language and culture in order to relate a product to a specific audience to increase sales, which is the process IS's publicity applies in order to increase foreign fighter recruitment rates [Figure 14]. Consider the major native language groups spoken by foreign fighters and IS supporters: Arabic, Russian, Turkish, French, and English. This is despite the fact that the majority of the world's Muslim population lives in South and Southeast Asia. The Wahabbi-takfir culture already exists in Indonesia, ${ }^{21}$ indicating an ideological pool for IS recruitment. IS has not sufficiently targeted

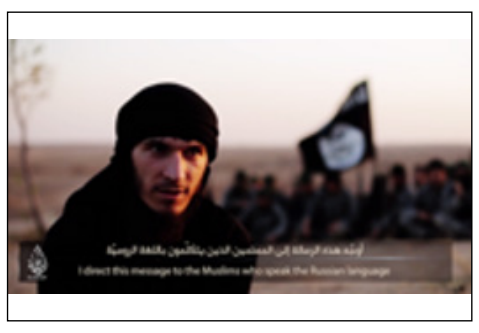

Figure 14: IS official recruitment video spoken in Russian with proper Arabic and English subtitles

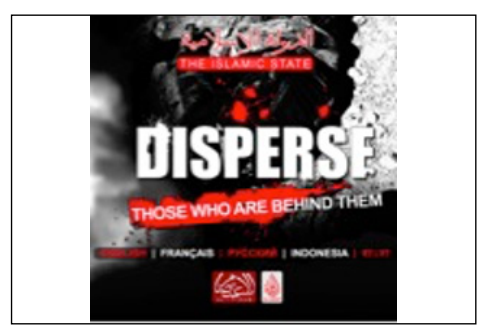

Figure 15: Fall preview of an IS Al-Hayat publication with an Indonesian language page ${ }^{(2014)}$

21. Sariburaja, Kennimrod. Al-Jama'ah Al-Islamiyyah. 13, Southeast Asia Regional Centre for Counter-Terrorism, Oct. 2013, Kuala Lumpur, Malaysia. 
correlates highly to the amount of localized information available in the language groups, meaning more localized IS content expands the IS market. The counter information campaign needs to be translated and localized for all the actual and potential recruitment pools, which is a task that can be distributed to member and partner nations.

1.7 Compose counter content from the viewpoint of Islamic State empathizers and vulnerable audiences in order to connect with the target audience.

Framing counter content from the viewpoint of IS empathizers and vulnerable audiences is paramount to avoiding counterproductive content such as [Figure 16]. The meme is designed to persuade foreign Muslim women to not travel to IS for marriage because Muslim women are forced into marriage with potentially unattractive partner(s). This meme is counterproductive because it contradicts testimonials of foreign Muslim women living in IS, whose word is more legitimate to the target audience. These pro-IS women state that IS respects their full rights as Muslims, which includes the right to accept or refuse a marriage proposal. The meme also assumes how the female Muslim target audience defines an attractive partner, causing the meme to be criticized by pro-IS social media users. Counter content designed to prevent young women and men from joining IS should be based on reasons to which they will relate and counterarguments to which they will agree.

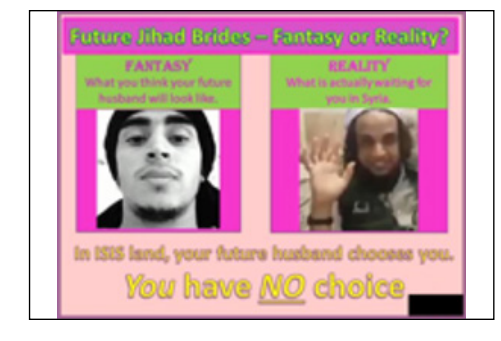

Figure 16: Anti-IS meme targeting unmarried foreign Muslim women $^{(2014)}$

1.8 Format counter content that resonates with the human aspect of the Islamic State community.

IS recruitment is not only about jihad fighters: it is aimed at non-combatant roles for women, children, and men who can contribute to all aspects of a community. Additionally, the importance of marriage and family is paramount for IS, meaning counter content needs to reflect the family oriented reasons for supporting IS [Figure 17]. When men and women consider going to IS territories, at a basic level, they are looking for stability in order to live and raise families. If IS cannot convince

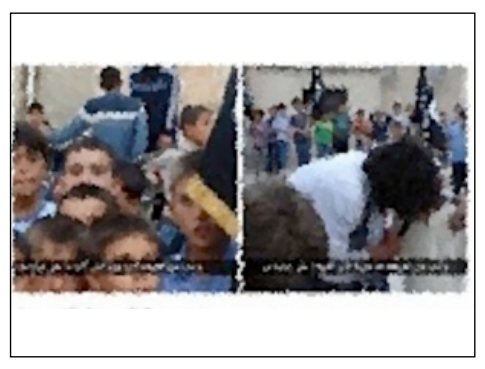

Figure 17: IS children's rally Syria(2014) 
women that the cities are safe for children, then they will be reluctant to come, making men reluctant to live without their families or without the possibility of marriage.

1.9 Format counter materials specific to female motivations for joining and supporting Islamic State in order to reduce the number of children raised to augment Islamic State forces.

Foreign women join IS for various reasons, and many are conscious of the realities [Figure 18]. This means there are foreign Muslim women who perceive rights and privileges to living in IS territories. There are women hesitant to join IS, but have an obligation to follow their partners who have left to fight for IS. This means counter materials should be formatted for this diverse reality among the female population in IS. This is important because pro-IS women support the

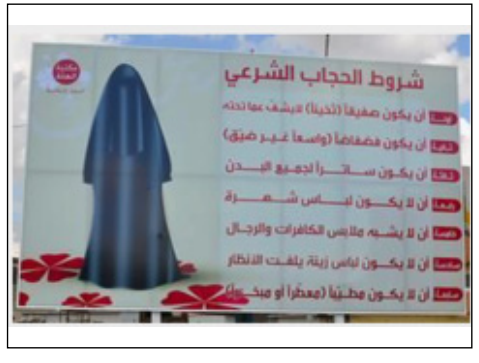

Figure 18: Publicly posted image of a woman's role in an IS city in Syria. fighter population and raise the children who will become IS's future adult population.

1.10 Design counter materials aimed at the global Islamic State virtual community in order to deter Islamic State militant movements outside of Syria and Iraq.

IS's broad recruitment strategy includes motivating supporters abroad as seen in [Figure 19]. The online recruitment pool lives in a violent virtual world on social media, and physically inhabits another country of residence. The framed reality online mixed with opposing realism means that pockets of IS communities present across the globe are stuck in a precarious existence. This necessitates counter materials to contrast peaceful lifestyles versus violent militant action for domestic security. As in the case of Libya, IS support grew to the extent of mass rallies [Figure 20] and, without overlooking Libya's grave internal security issues, Majlis Shura Shabab al-Islam in conjunction with Ansar al-Sharia thrusted the city of Darnah into an IS caliphate in April 2014.

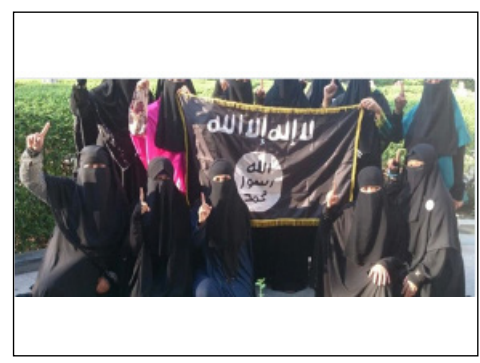

Figure 19: Female IS supporters in Indonesia.

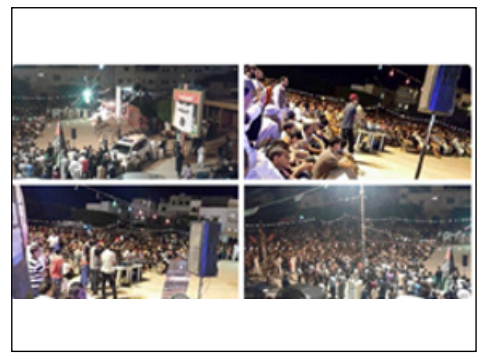

Figure 20: Pro-IS rally in Darnah (2014) 
1.11 Design counter materials for the generational culture of Islamic State jihad fighters and supporters so that the target audience is entertained by the messages.

Many foreign jihad fighters are aged 20-35, and come from NATO member states, meaning these individuals carry some cultural attributes relative to in-country residence. Several IS jihad fighters and supporters learned English from watching American movies and TV shows, and have a Western educational background. Many IS supporters and fighters have a sense of humor mirroring their generation indicating a manner in which we can communicate our message. IS supporter social media accounts entertain their

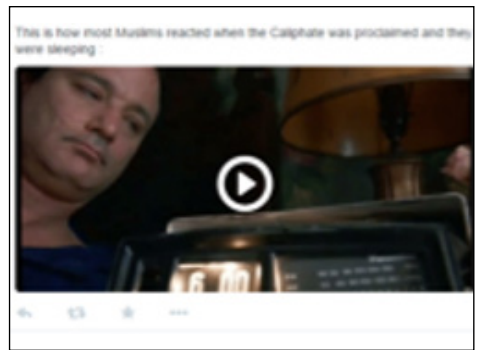

Figure 21: IS support social media account joking with a gif of Groundhog Day with Bill Murray(2014) followers as demonstrated in [Figure 21] which jokes how Muslims reacted to the establishment of the caliphate like the actor reacts to an alarm clock (smashing it). Instead of only employing serious counter content, humor can be an effectively disarming approach to target IS audiences.

1.12 Counter Islamic State online recruitment methods in real time in order to reduce the impact of trending comments, false news, and conspiracy theories.

IS recruiters and supporters quickly recognize opportunity with major global events in relation to IS's organizational needs. IS's social media campaign for Ferguson [Figure 22] represents how IS proliferates asymmetrically online. Within hours of the November protests in Ferguson, IS jihad fighters offered to liberate the city of Ferguson, and IS actually offered the protestors of Ferguson asylum in their controlled territories. Event tagging like this must be addressed in real time as part of an effective counter information program.

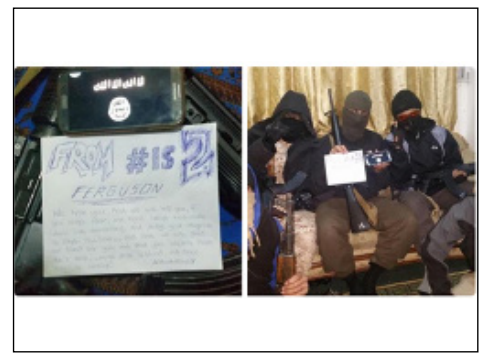

Figure 22: IS jihad fighters communicating to Ferguson protesters online ${ }^{(2014)}$ 
1.13 Monopolize on Islamic State's quick information dissemination and pro-Islamic State social media users who divulge valuable information.

IS jihad fighters provide news from the battlefield [Figure 23 \& 24] with live action camera-phone shots before established medias have the chance. This gives IS information control, which is the ultimate edge allowing them to flood the media market firstly and quickly. The disadvantage is that the mass of young and irresponsible online users means that valuable information is unintentionally divulged and can be turned for recruitment attrition. Even though accounts and websites provide a platform for direct and indirect recruitment, the information gained from allowing these users to operate blindly gives us an opportunity for intelligence gathering to assist both military and legal measures.

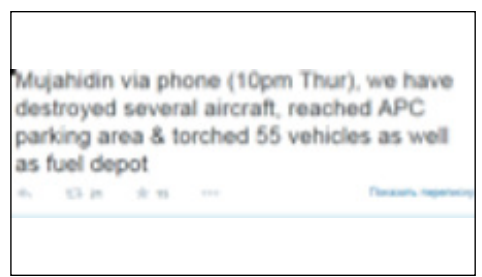

Figure 23: Pro-IS Afghan affiliate Twitter account reporting on the attacks at Shorabak

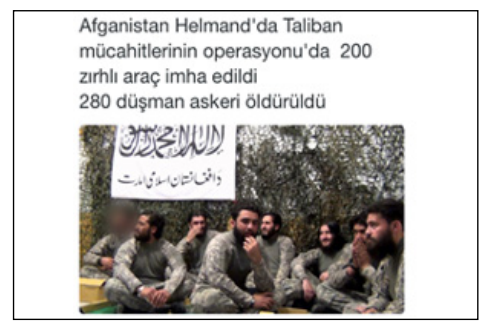

Figure 24: Pro-IS Afghan affiliate Twitter account reporting in Turkish during the Shorabak attacks in November (2014)

1.14 Utilize social media accounts to subtly erode credibility of major Islamic State recruiters and proponents on social media.

The long-term plan needs to focus on decreasing follower support on an ideological basis, which means eroding credibility as followers define it. Even though there are benefits to account and website suspension, in some cases it is more beneficial to let certain accounts operate blindly in order to subtly erode their influence. Additionally, suspended IS recruiter accounts and websites reappear quickly in different forms [Figure 27], and gain hundreds of followers within a few days. Pro-IS social media users are operationally mutative in that they adapt to suspension by disguising the account, thus making them more difficult to find and track [Figure 26]. In this case the approach is critical, since pro-IS accounts easily identify and block suspicious activity [Figure 25].

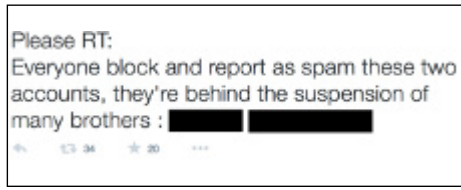

Figure 25: IS supporter Twitter account reacting to trolls

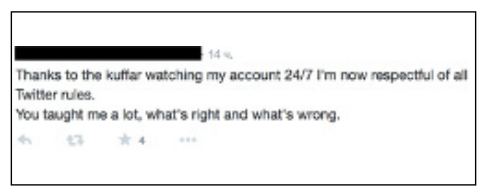

Figure 26: IS supporter Twitter reacting deceptively to multiple suspensions, and adapting to hide the account

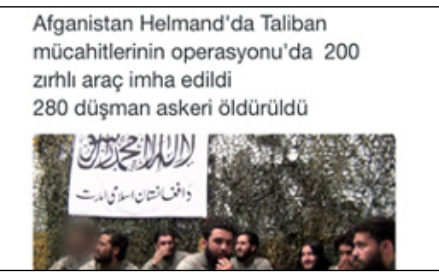

Figure 27: IS supporter Instagram account on the 5th try ${ }^{(2014)}$ 


\section{Conclusion}

The fact that IS can channel the anger, frustration, and confusion present in Muslim communities for direct support or impartiality for IS, is the most powerful psychological element of IS recruitment. The ideological popularity of ShamiWitness demonstrates this phenomenon: he actually gained support by framing Qur'an and Hadith knowledge with the persecution and oppression of Muslims, and the belief of a war against Islam. These beliefs bolster global Sunni Muslim community support for a caliphate to which IS took the lead on a local level.

IS's grass roots and local community building is another aspect of asymmetric information strategy, which is a related issue requiring different counter measures. IS members literally go door to door [Figure 28] to communicate with written and spoken messages. Countering IS community building within Syria, Iraq, Libya, and Afghanistan with cultural intelligence is paramount, but involves realities necessitating a different type of counter information structure than social media.

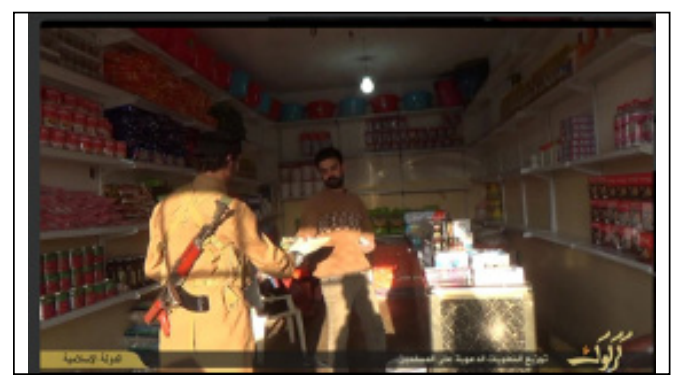

Figure 28: IS jihad fighter distributing propaganda materials in Syria ${ }^{(2014)}$

Essentially, there is no one Muslim culture more vulnerable to IS recruitment because the quality and quantity of localized information directly influences the success of the information campaign, which is reflected in IS's major foreign language groups. With multilingual materials, IS recruits a lifestyle that siphons from the radical periphery of modern Wahabbism. This violent form of Wahabbi-takfir ideology transcends IS because it seeks to purge the Muslim community, which is why it should be approached as a global social crisis.

The Alliance has an important role in combating online recruitment to lower domestic security threats inside Alliance member states, and to assist NATO Partners' security dilemmas. With a long-term dedicated counter information campaign, global and domestic recruitment attrition is attainable. In a broader scope, similar information campaigns and advanced cultural analysis can be applied to any type of security challenge faced by NATO Member nations to assist in cyber warfare, counter terrorism, counter insurgency, and other developing security issues. 


\section{References}

Al-Abdeh, Malik. "The Transition of Groups from Terrorism in Insurgency and the Case of Population Support of Syria." NATO COE-DAT Terrorism Experts Conference, 2014, Turkey. Conference Presentation.

Borison, Rebecca. "Twitter Suspended An ISIS-Affiliated Account That Called For The Assassination of Twitter Employees." Business Insider, 9 Sep. 2014, http://www.businessinsider.com/twitter-suspended-isis-affiliated-account-that-called-for-its-assassination-2014-9. Accessed 9 Sep. 2014.

Feyyaz, Muhammad. "Voids, Limitations and Their Implications in National Counter-Narrative for CT - A Case of Pakistan." NATO COE-DAT Terrorism Experts Conference, 2014, Turkey. Conference Presentation.

Pirinççi, Ferhat, Oytun Orhan and Bilgay Duman. "US Strategy Against ISIS and Its Potential Implications for Iraq \& Syria." ORSAM, Sep. 2014, http://www.orsam.org.tr/en/enUploads/ Article/Files/2014924_rapor191ing.pdf. Accessed Sep. 2014.

Rouiller, Jean-Paul. "From MM (for Mohamed Merah) to MN (Mehdi Nemmouche) or the Foreign Fighters Shifting Paradigm." NATO COE-DAT Terrorism Experts Conference, 2014, Turkey. Conference Presentation.

Sariburaja, Kennimrod. Al-Jama'ah Al-Islamiyyah. 13, Southeast Asia Regional Centre for CounterTerrorism, Oct. 2013, Kuala Lumpur, Malaysia.

Votel (General), Joseph. "Operating in the Human Domain." USSOCOM Publication, 3 Aug. 2015.

Zelin, Aaron Y. "The Islamic State's First Colony in Libya". The Washington Institute, http://www. washingtoninstitute.org/policy-analysis/view/theislamic-states-first-colony-in-libya. Accessed 10 Oct. 2014.
"Afghan Troops 'Drive Out' Taliban From Key Southern Base." RFERL Afghanistan, 15 Dec. 2014, http://www.rferl.org/content/helmand-attack-afghanistan-shorabak-camp-bastion/26714774.html. Accessed 15 Dec. 2014.

"Learn from Yesterday, Gain for Tomorrow NATO's Counter-Terrorism Experience in Afghanistan". Lessons Learned Workshop, NATO COE-DAT, 18 Nov. 2014, Ankara, Turkey.

"@shamiwitness: India arrests man over pro-lslamic State tweets." BBC Asia, 13 Dec. 2014, http://www.bbc.com/news/world-asia-30461455. Accessed 13 Dec. 2014.

"Islamic State crisis: '3,000 European jihadists join fight." BBC, 26 Sep. 2014, http://www.bbc.com/ news/world-middle-east-29372494. Accessed 26 Sep. 2014. 